\title{
A IMPORTÂNCIA DO ENSINO DE FILOSOFIA EM UMA ESCOLA DO CAMPO FRUTO DO PROCESSO DE REFORMA AGRÁRIA
}

\section{Michele Barcelos Corrêa ${ }^{1}$}

\begin{abstract}
Resumo: O objetivo do estudo consiste em abordar a importância e contribuições do ensino de Filosofia a educação no/do campo para o processo de formação de cidadãos. A escolha da escola para o desenvolvimento das observações se deve ao contexto de ameaça de fechamento de escolas em áreas rurais por parte do governo do Estado do Rio Grande do Sul, fazendo-se preciso evidenciar a qualidade e a importância da educação do campo como forma de resistência na defesa da educação pública e de qualidade para todos e todas, especialmente o povo campesino. Para tanto são apresentadas as diversas concepções filosóficas presentes na História da Filosofia, a presença do ensino de filosofia na educação brasileira, a importância do seu ensino no Ensino Médio e sua contribuição à educação no/do campo. A hipótese levantada é de que o Ensino de Filosofia contribua para a formação de indivíduos emancipados indo ao encontro da proposta educacional da educação no/do campo, a qual tem por base as contribuições do educador brasileiro Paulo Freire e forte influência do processo pedagógico do Movimento dos Trabalhadores Sem-Terra (MST). Os resultados encontrados permitem afirmar que o ensino de Filosofia, capacita os estudantes para o diálogo, o debate de ideias.
\end{abstract}

Palavras-chave: Ensino de Filosofia. Ensino Médio. Educação do Campo.

\begin{abstract}
The purpose of the study consists in approach the importance and contributions of the Philosophy study to the education in/of the countryside to the citizen formation process. The choice of school for the observations development is due to the threat context of schools closure in rural areas by the Rio Grande do Sul's government, making it necessary to highlight the quality and importance of the rural education as a resistence form in the defense of public and quality education for all, especially the peasant people. For this the many philosophic conceptions present in the Philosophy History are presented, th presence of Philosophy teaching in Brazilian education, the importance of it's teaching in High School and it's contribuition to the education in/of the countryside. The hypothesis raised is that the Philosophy teaching contributes to the formation of emancipated individuals meeting the educational proposal of education in/of the countryside, which is based on the contributions of the brazilian educator Paulo Freire and strongly influenced by the pedagogical process of Movimento dos Trabalhadores Sem-Terra (MST). The results found allows to affirm that the Philosophy teaching empowers the students to dialog and debate of ideas.
\end{abstract}

Key words: Philosophy teaching; High School; Countryside Education.

1 Graduanda em Licenciatura em Filosofia na Universidade Federal de Pelotas. Currículo Lattes: http://lattes.cnpq.br/3797197424737312. 


\section{Introdução}

Para o bem compreender a interligação entre Ensino de Filosofia e Educação do/no campo é preciso um olhar atencioso para a localização desta escola e seu contexto econômico e sociocultural. A E. E. E. M. 15 de Junho localiza-se na zona rural, no Assentamento de Reforma Agrária Conquista da Fronteira, em Hulha Negra, município da Região da Campanha Gaúcha, e atende, alunos e alunas oriundos de outros 15 assentamentos próximos à mesma. $\mathrm{A}$ maioria das famílias residentes nos assentamentos possuem escolaridade apenas nas séries iniciais, cerca de $50 \%$ não tem o $6^{\circ}$ ano do Ensino Fundamental, $40 \%$ possui Ensino Fundamental Incompleto e, aproximadamente, $10 \%$ têm formação no ensino superior. As pessoas que moram na área de abrangência da escola, trabalham na terra, tendo a agropecuária como sua principal ocupação. Há também quem além de trabalhar a terra, se dedica a outras ocupações como: pedreiro, carpinteiro, professor, agentes de saúde, motoristas, entre outras. Muitos filhos e filhas dos assentados, após concluírem o ensino Médio na escola, deixam de morar na região, em busca de trabalho e/ou sustentação para a vida com empregos nas cidades vizinhas ou em outras áreas de produção agrícola ${ }^{2}$.

Com o objetivo de estar voltada para as necessidades e oportunidades presente em seu contexto em seu Projeto Político Pedagógico (PPP), a escola prima por uma educação: Para transformação social; Para o trabalho do meio na qual está inserida (assentamento) e a cooperação; Voltada para as várias dimensões da pessoa humanista; Como processo permanente de formação e transformação humana, compreender a escola como um espaço emancipatório e como um território fecundo de construção da democracia e da solidariedade. Para tanto a comunidade almeja uma educação de classe, massiva, orgânica, aberta para o mundo, voltada para a ação é aberta para o povo. Isso implica em concepções educativas, culturais, econômicas e ambientes para o campo, mas não apenas para o campo, e sim para toda sociedade.

Assim, o PPP da escola apresenta os seguintes objetivos pedagógicos: compreender o ambiente natural e social, o sistema político, a tecnologia, as artes e os valores em que se fundamenta a sociedade, desenvolver a construção de competências e habilidades, bem como o fortalecimento dos laços de solidariedade humana, voltados a vida social, respeitando as diversidades culturais; desenvolver nos educandos as habilidades, bem como construir as

\footnotetext{
${ }^{2}$ Fonte: Projeto Político Pedagógico (PPP) da E. E. E. M. 15 de Junho.
} 
aprendizagens necessárias para a formação integral de indivíduos autônomos e capazes do pleno exercício da cidadania, articuladas com as causas do campo visando fixar e desenvolver os educandos para atuarem em suas realidades e transformando-as.

A justificativa para a realização do trabalho a partir das observações realizadas nesta escola vem fundamentada na observação do ensino de Filosofia como parte importante para que a escola alcance seus objetivos educacionais, onde a educação é voltada para a construção de conhecimento e troca de saberes, implicando em concepções educativas, culturais, econômicas e ambientes para vivência no/do campo, de maneira a permitir aos jovens de famílias estabelecidas e oriundas de áreas de assentamentos da reforma agrária, e assim os processos educativos se desenvolvam visando a emancipação dos alunos e alunas como sujeitos, contribuindo para a formação humana dos jovens estudantes de forma a empoderá-los de consciência crítica e autonomia, necessários a luta para conquistar direitos humanos, sociais, civis, políticos e ambientais.

Dessa maneira, o objetivo do estudo consiste em abordar a importância e contribuições do ensino de Filosofia à educação no/do campo para o processo de formação de cidadãos, para tanto é abordada a importância do ensino de filosofia no médio, tendo como objetivos especificos apresentas as principais concepções filosóficas da educação, refletir o ensino de filosofia na educação brasileira, discutir o porquê de ensinar filosofia no ensino médio, visando constatar a validade ou não da hipótese levantada, a qual se refere a contribuição do Ensino de Filosofia para a formação de indivíduos emancipados indo ao encontro da proposta educacional da educação no/do campo, a qual tem por base as contribuições do educador brasileiro Paulo Freire e forte influência do processo pedagógico do Movimento dos Trabalhadores Sem-Terra (MST).

Segundo Santos e Knaben (2015) percebe-se que para pensar o campo brasileiro com sua diversidade é necessário refletir qual educação está sendo oferecida no meio rural e qual a concepção de educação está presente nesta oferta. Para tanto deve-se considerar a educação do/no campo com um olhar atento aos objetivos da educação dando ênfase ao papel da educação para as comunidades campesinas no que tange suas necessidades e realidades. Assim, se faz necessário esclarecer que a Educação do/no Campo tem pouco mais de uma década, tendo surgido a partir da luta dos movimentos sociais dos camponeses (Movimento dos Trabalhadores Sem-Terra, Movimento dos Pequenos Agricultores e Sindicatos Rurais, entre outros), 
juntamente a luta pela Reforma Agrária, onde estes camponeses lutam para garantir uma melhor qualidade de vida.

Segundo Serra e Sobrinho (2013, p. 143), sem educação a reforma agrária não é completa. Pensando dessa forma o Movimento dos Trabalhadores Rurais sem Terra (MST) propôs e conquistou a institucionalização de uma proposta de educação no campo, uma educação que fosse apropriada a realidade dos estudantes das áreas rurais. Sendo pregado pela proposta pedagógica do movimento que, além da terra, é preciso que os camponeses tenham acesso a uma educação transformada, não igual, mas diferente da ofertada na cidade e no próprio campo, de forma a ser uma educação condizente com sua realidade dos estudantes oriundos de um movimento social que busca por meio da reforma agrária a inserção destes trabalhadores e trabalhadoras no processo econômico.

Embora com significados diferentes, educação e escola são termos que geralmente caminham juntos, onde "a educação, termo que engloba o sentido da escola, trazendo em seu significado a formação integral do indivíduo tão cara ao MST, incluindo não só a escola, mas todas ações e atos que levam a construção sistematizada do conhecimento acumulado ao longo da história da humanidade" (SERRA E SOBRINHO, 2013, p. 148).

A chamada pedagogia do MST que inspira sua luta pela manutenção das Escolas de Educação no Campo, conquistadas na década de 1990, tendo por bases teóricas as propostas de Paulo Freire, o mais célebre educador brasileiro. Freire teve como grande objetivo de sua vida como educador transformar a educação em um mecanismo de conscientização do sujeito em favor de sua própria libertação. De maneira que por meio da educação os sujeitos percebam a opressão, a qual estão sujeitados, percebendo-se oprimidos e assim busquem a sua libertação, os principais conceitos da pedagogia libertária de Paulo Freire são apresentados em sua obra "Pedagogia do Oprimido", obra de 1968, referência para os movimentos sociais, em especial o MST. Freire na Obra "Pedagogia da Esperança" de 1992, chama a atenção para algo importante de sua obra "Pedagogia do Oprimido", a relação entre a clareza política na leitura do mundo e os níveis de engajamento no processo de mobilização e de organização para a luta, para a defesa dos direitos e para a reivindicação de justiça (FREIRE, 2016).

\section{Metodologia}


Este trabalho é um relato de experiência resultado de observações acerca do Ensino de Filosofia em turmas do Ensino Médio da E. E. E. M. 15 de Junho desenvolvidas nas disciplinas de Estágio I e II, da graduação em Licenciatura em Filosofia, da Universidade Federal de Pelotas, Polo UAB Hulha Negra.

Para o bem compreender da metodologia adotada no trabalho é necessário explicitar o que podemos compreender como filosofia, ou seja, qual o seu significado. Partindo da definição de filosofia como amor ao saber, é considerado importante dizer que isso não significa que possamos reduzir a tarefa do filósofo a "um saber sui generis, reservado a uns poucos interessados, como um tipo de saber complicado e inacessível a todo indivíduo. Ao contrário, como indicado na alegoria da caverna de Platão, sair da caverna é tarefa de todo e qualquer ser humano, onde a filosofia é o vislumbrar de um horizonte de conhecimento almejado, que jamais poderá ser tocado por completo" (BARBOSA, 2015, p. 15).

Para o desenvolvimento da pesquisa é preciso definir para a sua condução o método, caminho pelo qual a pesquisa será guiada para alcançar seus objetivos. A escolha do método deve partir do objetivo que se deseja alcançar com o estudo. Neste caso o método escolhido é a Pesquisa Filosófica, onde para a sua realização, foi necessária, antes de tudo, a coleta de dados referentes ao assunto pretendido, sendo que é essa coleta que dará o suporte para a pesquisa. Após a coleta de dados, foi realizada a leitura completa do material. Posteriormente, escolheuse qual tipo de pesquisa utilizar para realizar o estudo. Nesse momento, foram confrontados os dados, as evidências, as informações coletadas sobre o assunto e o conhecimento teórico acumulado a respeito dele. Essa foi uma fase importante da pesquisa, pois foi o momento em que foi reunido o suporte teórico (técnico) para compreender melhor as discussões acerca do assunto (BARBOSA, 2015, p. 27).

Na condução deste estudo foi escolhido como método de coleta de dados a pesquisa com foco no objeto, a partir de uma pesquisa bibliográfica, cujo objetivo foi a leitura e análise de materiais já publicados, tais como livros, artigos, periódicos, monografias, dissertações e teses. A pesquisa bibliográfica é acompanhada de estudo de caso, esse tipo de procedimento diz respeito ao estudo aprofundado de um ou poucos objetos e situações que permite que façamos uma interpretação detalhada de algo. Em geral, o estudo de caso envolve uma determinada situação que nos propomos interpretar e avaliar, com o intuito de adquirir determinado conhecimento sobre ela, neste caso o ensino de Filosofia na Escola. Complementada por uma pesquisa com foco no problema, de caráter qualitativa, modalidade 
de abordagem do problema busca estabelecer uma relação entre o sujeito e o objeto, tendo em vista que os objetivos a serem alcançados a partir deste estudo não serem passíveis de tradução em números, ou seja, a problemática caracteriza-se por ser descritiva, assim o pesquisador necessita analisar os dados no processo indutivo, não permitindo que os resultados obtidos possam ser quantificáveis (BARBOSA, 2015, p. 32-35).

As observações ocorreram semanalmente durante os meses de outubro, novembro e dezembro de 2019, onde a carga horária das observações foi de 12 períodos de aula (50 minutos cada período) em sala de aula, 06 períodos em atividades interdisciplinares (sendo três períodos referentes a apresentação de trabalhos durante a atividade interdisciplinar festa Anos 80 e 03 períodos referentes apresentações de trabalhos na Feira do Conhecimento promovida pela Escola) e dois períodos referentes ao dia D, como apresentado no Quadro A, Observações das Turmas de Ensino Médio, em Anexo.

Com o objetivo de ter um olhar e compreensão integral da gestão de classe da disciplina Filosofia na Escola foi solicitado a Professora Regente (PR) permissão para o acompanhamento das três turmas de Ensino Médio, sendo elas, turma de $1^{\circ}$ ano, de $2^{\circ}$ ano e $3^{\circ}$ ano, pois a mesma é regente das três. De maneira que fosse possível observar os conteúdos, atividades e avaliações referentes a integralidade do ensino de Filosofia na escola.

A PR assumiu a regência das turmas no mês de julho de 2019, é a primeira vez que a mesma ministra a disciplina de Filosofia, assim reelaborou os planos de ensino da disciplina para as turmas, os conteúdos são ministrados seguindo os planos, onde são utilizados recursos lúdicos e digitais.

A Professora Regente foi aluna da Escola desde o início da Instituição em agosto de 1989, tendo permanecido na mesma até a $5^{\text {a }}$ série, mudando de escola em virtude de a escola ainda possuir as séries seguintes, tendo retornado à instituição como docente quando formada em Pedagogia. Atualmente possui pós-graduação na área de inclusão atuando na Sala de Recursos da escola, é graduanda em Licenciatura em Letras pela Universidade Federal do Pampa (UNIPAMPA) e leciona na Escola além da disciplina de Filosofia, as disciplinas de Sociologia, Religião, Geografia e Espanhol nas três turmas do Ensino Médio, totalizando 13horas/aulas semanais.

A turma do $3^{\text {a }}$ Ano do Ensino Médio é uma turma, onde as idades variam em uma faixa etária de 17 a 18 anos, com exceção de uma aluna adulta de 54 anos. É uma turma bastante 
participativa. A turma do $2^{\circ}$ Ano é uma turma majoritariamente composta por meninas, assim como a turma do $3^{\circ}$ Ano é bastante participativa. A turma do $1^{\circ}$ Ano é a mais agitada, onde há maior conversa durante a aula. Os alunos e alunas costumam sentar-se em duplas ou trios durante as aulas, sendo turmas pequenas geralmente ocupam um lado da sala, o próximo ao corredor, talvez para não ficarem próximos das janelas.

As relações entre os alunos e alunas e entre discentes e docentes é harmoniosa, marcada por amizade e confiança. Os alunos são participantes, sempre dispostos, apresentam boa participação em aula, assim como acolheram com carinho e respeito minha presença durante as suas aulas. A turma de $1^{\circ}$ Ano é a turma mais agitada, é possível perceber que a PR prepara a aula dispensando especial atenção a esta turma, de maneira que a aula permite interação sem dispersão dos alunos.

Em aula ministrada na Turma 301, com o tema "Direitos Humanos" a PR iniciou a aula fazendo memória da aula anterior, cabe aqui explicitar que a turma estava organizada de maneira a formar um semicírculo, permitindo que todos pudessem se olhar enquanto dialogavam. $\mathrm{Na}$ aula anterior os alunos haviam realizado a leitura do conteúdo referente ao tema no livro da disciplina e como tema a tarefa de elaborar questões sobre o tema. Após a recordação a aula anterior a PR passou uma caixa na qual continha alguns papéis contendo escritos os direitos humanos, de maneira que cada aluno ao pegar um papel, este papel conteria um direito humano sobre o qual ele deveria falar a turma, podendo os colegas contribuir na explanação. Assim, todos os alunos tiveram a oportunidade de realizarem explanações acerca dos direitos humanos, onde após esse momento a PR passou um vídeo de 3 minutos onde é relatado o surgimento dos direitos humanos, de maneira de ilustrar cada um do referidos direitos. A aula é finalizada após uma roda de debate que permitiu os alunos refletirem e dialogarem sobre as situações onde os direitos humanos são violados, tendo a oportunidade de confrontar o conteúdo teórico com suas experiências de vida.

Em aula ministrada na turma 201, com o tema "Crise da Metafísica" a PR abordou a vida e obra de René Descartes, iniciando a aula com a memória da aula anterior, na qual os alunos realizaram leitura do capítulo referente ao filósofo a ser estudado, e logo em seguida a PR procedeu uma apresentação da síntese do conteúdo em Power Point. Em virtude de nesta turma disponibilizar apenas um período semanal de 50 minutos, a exposição dos conteúdos ocorre de maneira mais tradicional, porém sem deixar de privilegiar o diálogo e exposição por parte dos alunos, onde os mesmos expõe suas próprias reflexões sobre os conteúdos abordados. 
Em aula ministrada na Turma 101, a PR introduziu o conteúdo "Valores Humanos" entregando uma folha em branco a cada aluno pedindo que fosse escrito o que eles entendem por valores humanos, foi dado 10 minutos para que essa atividade fosse realizada, após transcorrer o tempo a PR recolheu as folhas e entregou a cada aluno um papel contendo um dos conceitos apresentados como valor humano. Assim, solicitou que um aluno dissesse qual foi o valor humano que recebeu e qual entendimento tinha acerca desse valor, logo após a explanação do aluno a PR apresenta o conceito teórico sobre o referido valor em Power Point, assim todos os alunos tiveram oportunidade e explanar sobre um valor humano. Após a exposição de todos os valores humanos, as folhas onde os alunos haviam escrito no início da aula foram entregues de maneira que cada aluno tenha pego a escrita por um colega, depois de acordado entre os alunos a exposição de seus escritos foi realizada a partilha, onde foi possível perceber que os mesmos estavam muito conscientes sobre os conceitos e práticas referentes aos valores humanos. A reflexão acerca dos valores, especialmente quanto ao valor respeito foi utilizado pela PR para mediar um conflito existente na turma, pois no início da aula uma aluna havia reclamado que um dos colegas, o qual não sabia quem ser, havia escrito em sua mochila sem sua permissão. A partir da reflexão realizada pelos alunos durante a aula sobre os valores humanos, a PR os levou a refletir o fato, solicitando que o aluno, ou os alunos, que agiram de tal maneira refletissem e se achassem por bem pedir desculpa a colega o fizessem em oculto.

A PR possui uma relação de amizade e parceria com os alunos e alunas, pode-se perceber um grande respeito entre discentes e docente. A PR prepara a aula e a exposição dos conteúdos de maneira que seja possível contextualizar com a realidade vivida pelos alunos e alunas, promovendo o desenvolvimento do senso crítico dos mesmos, inter-relacionando os conteúdos teóricos da disciplina de filosofia com os saberes dos alunos e alunas, bem como as experiências e vivências vividas nas comunidades onde os mesmos estão inseridos.

Paulo Freire (2018, p. 16) nos diz que formar é muito mais que do que puramente treinar o educando no desempenho de destrezas, frisando a responsabilidade ética no exercício da tarefa docente. Assim é possível perceber na prática docente da PR uma orientação de base freireana, onde a mesma, muito mais que passar conteúdos, se compromete na troca de saberes de maneira a construção de novos saberes a luz da ética universal do ser humano.

As aulas apresentam boa distribuição de tempo, nas turmas de $1^{\circ}$ e $3^{\circ}$ ano a professora fez opção de juntar os períodos da disciplina de filosofia e sociologia, os quais são um período semanal cada uma, assim em uma semana são ministrados dois períodos de filosofia e na 
semana seguinte dois períodos de sociologia, permitindo dessa forma que possa ser preparada uma aula mais participativa com o uso de uma maior diversidade de recursos. Nas aulas são usados recursos audiovisuais, jogos pedagógicos e dinâmicas de maneira que aula seja bastante interativa. A disciplina é trabalhada de maneira interdisciplinar e contextualizada com a realidade vivida pelos alunos e alunas em suas comunidades e na comunidade onde a escola está inserida. Um exemplo foi um trabalho interdisciplinar com caráter avaliativo no qual foram envolvidas todas as turmas da escola. O trabalho consistiu em uma pesquisa sobre a década de 1980, década na qual foi constituído o assentamento Conquista da Fronteira, comunidade na qual a escola está inserida, bem como marca também a chegada dos colonos assentados a região. Assim a pesquisa teve como objetivo abranger todas as áreas do conhecimento, sendo os trabalhos expostos em uma sala, como um grande memorial, de maneira a permitir um passeio pela década de 1980, como um túnel do tempo, e bem como uma festa Anos 80, onde os alunos foram desafiados a reproduzir o estilo de vida dos jovens dessa década.

\section{A Importância do Ensino de Filosofia no Ensino Médio}

O filósofo André Comte-Sponville (2003, p. 251-252) relata o seguinte diálogo:

[...] A cena se desenrola no início do século XX, num lugarejo da França Rural. Um jovem professor de filosofia passeia com um amigo e encontra um camponês, que seu amigo conhece, lhe apresenta e com o qual nosso filósofo troca algumas palavras.

- O que o senhor faz? — Indaga o camponês.

— Sou professor de filosofia.

— Isso é profissão?

— Por que não? Acha estranho?

- Um pouco!

-Por quê?

— Um filósofo é uma pessoa que não liga para nada... Não sabia que se aprendia isso na escola.

O filósofo na sequência do texto no qual narra o diálogo comenta:

O que é um filósofo? É alguém que pratica a filosofia, em outras palavras, que se serve da razão para tentar pensar o mundo e sua própria vida, a fim de se aproximar da sabedoria ou da felicidade. E isso se aprende na escola? Tem que ser aprendido, já que ninguém nasce filósofo e já que a filosofia é, antes de mais nada, um trabalho. Tanto melhor, se ele começar na escola. $\mathrm{O}$ 
importante é começar, e não parar mais. Nunca é cedo demais nem tarde demais para filosofar, dizia Epicurio [...]. Digamos que só é tarde demais quando já não é possível pensar de modo algum. Pode acontecer. Mais um motivo para filosofar sem tardar (SPONVILLE, 2003, p. 252).

Em seu comentário Sponville evidência um conceito de filósofo e de filosofia, os quais são configurados como trabalho devendo ser aprendidos na escola, explicitando a importância do ensino de filosofia, pois nas palavras do autor ninguém nasce filósofo ou filósofa (ARANHA, 2012, p.15). Para bem compreender as configurações do conceito de filósofo e de filosofia é importante conhecer as principais concepções de filosofia da educação construídas ao longo da história.

\section{As Principais Concepções Filosóficas da Educação}

Nascida na Grécia, a filosofia, palavra usada pela primeira vez por Pitágoras, (philos= amor; sophia = saber, entendida como "amor pela sabedoria"), está comprometida com a paideia (educação formadora), podendo ser conceituada como um conhecimento sistematizado que procura explicar racionalmente o que é a totalidade das coisas, de maneira integral, sem exclusão de partes ou de momentos, buscando assim compreender o homem e o mundo, bem como a educação deste homem que vive no mundo, permitindo que a prática educativa apresenta uma visão do homem e do mundo incluindo assim uma posição filosófica (VALEIRÃO, 2014, p. 13).

A relação entre filosofia e educação pode ser pensada a partir do entendimento de que a educação está repleta de sentidos, de conceitos, de valores e de finalidades que nos levam a questionamentos acerca do próprio sentido da educação na e para a sociedade. De maneira que podemos perguntar "que sentido pode ser dado à educação, como um todo, dentro da sociedade?".

Ao longo da história da Filosofia alguns filósofos se dedicaram a pensar a questão da educação a partir dos quais podemos destacar três principais concepções filosóficas sintetizadas em três perspectivas: a Essencialista (Referência Metafísica), onde a educação é um processo de atualização da potência da essência humana, visa critérios de ação propriamente éticos; a naturalista (referência científica, na qual a educação é considerada um processo de desenvolvimento de um organismo vivo com potencialidades físicas, biológicas e sociais inscritas no homem, almejando critérios de avaliação fundamentalmente técnicos e para a 
dialética (referência histórico-social) a educação é um processo individual e coletivo de constituição de uma nova consciência social, visando critérios de avaliação da ação e da educação eminentemente política (VALEIRÃO, 2014, p.15).

Segundo Sócrates (470/469-399 a.C.), fundador da filosofia ocidental, a educação estava fortemente comprometida com o conhecer o mundo e a si mesmo. Sendo popularmente conhecido como autor da frase "Conhece-te a ti mesmo". O problema da dependência do aluno em relação ao professor era visto pelo filósofo como uma deficiência na educação, pois quando Sócrates iniciou o seu trabalho, o conhecimento era tratado como uma forma de comércio, onde o aluno pagava o professor. Sócrates classificou esses professores de Sofistas, seus métodos eram baseados na decoração de conteúdos e discursos prontos, levando os seus alunos a preocupar-se mais com as afirmações e conteúdo prontos do que com a arte de questionar e perguntar, tornando-se pessoas passivas e acríticas em relação ao conhecimento. Ao contrário, Sócrates acreditava que apenas um verdadeiro diálogo poderia levar a uma verdadeira troca de conhecimento (TEIXEIRA et. al, 2015, p 46).

Platão (427-347 a.C.), na obra República (376 a. C.)a alma precede o corpo e antes de encarnar tem acesso ao conhecimento, assim o aprendizado é um esforço de recordação de um conhecimento que está na memória. O discípulo de Sócrates era contra métodos de ensino autoritários, defendendo que os estudantes deviam ser deixados à vontade para aprenderem livremente. A filosofia platônica se constitui a partir da tentativa de encontrar solução para o problema do conhecimento. Assim, "as respostas tanto ao problema do conhecimento, quanto aos problemas filosóficos, éticos e políticos de seu contexto filosófico e histórico aparecem em A República. Nessa obra é permitido compreendermos como Platão entende a filosofia e idealiza o filósofo como educador do Estado e dos cidadãos, conferindo a ele um papel central no funcionamento da cidade ideal, ampliando os ensinamentos de seu mestre Sócrates e construindo as bases de seu próprio um pensamento e pedagogia, não abordando apenas os problemas historicamente vividos e pensados relativos à filosofia e à Paideia, como também demarcando a história da filosofia da educação" (PAGNI, 2010, p. 2).

Aristóteles (384-322 a.C.), discípulo de Platão defendia que mundo antecede o conhecimento e a ciência, afirmando que o princípio da aprendizagem deveria se dar por imitação, onde os hábitos se formam por meio do exemplo, diferente do imaginado por Platão, o sistema de ensino postulado por Aristóteles era mais acessível a um número maior de pessoas, propondo uma educação que tem início na infância, momento em que a criança recebe as 
primeiras lições, e que se estende ao jovem que deve receber uma educação pública, ser educado também na pólis. Onde “essa educação perpassaria toda a vida do cidadão adulto, devendo todas as etapas do aprendizado corroborar com a eudaimonía. Para tanto, aquele que educa e aquele que é educado necessitam saber das tendências naturais dos homens a fim de aprimorá-las ou controlá-las quando conveniente, surgindo assim a necessidade de educar também àquilo que o Aristóteles chama de parte irracional da alma, a qual comporta o desejo que, junto com as demais paixões, devem ser "domesticados" pelos bons hábitos, facilitando uma vida virtuosa e feliz, caminho para a eudaimonía" (VALEIRÃO, 2014, p.15).

Segundo Agostinho (354 - 430), o homem tem acesso do conhecimento por meio de iluminação divina. Assim, cabe ao professor apresentar o caminho e ao aluno o adotar, brotando o saber de seu interior. Não sendo o educador um transmissor do saber, mas aquele que desperta o saber no aluno, para que o mesmo desse modo posso encontrar a paz da alma, objetivo final da educação. O filósofo distingue duas formas de conhecimento: o conhecimento das coisas sensíveis e o conhecimento das coisas inteligíveis. "Os conhecimentos sensíveis são aqueles que provém dos sentidos, são levados à memória e organizados pelo homem, porém, os conhecimentos das coisas inteligíveis, que não provém dos sentidos, são compreendidos por meio de uma reflexão interior realizada pelo homem. Assim, os sentidos, funcionam apenas como um meio de estimular o indivíduo a autorreflexão" (RUBANO, MOROZ, 2001 apud SOUZA, 2009, p. 2461)

Para Tomás de Aquino (1224 - 1274) o método de ensino não se resume a transmissão de conhecimento, mas ao entendimento de que o conhecimento é construído pelo aluno, existindo assim duas formas de se adquirir conhecimento: “[...] de um modo, quando a razão por si mesma atinge o conhecimento que não possuía, o que se chama descoberta; e, de outro, quando recebe ajuda de fora, e este modo se chama ensino" (TOMÁS DE AQUINO, 2000).

Em Tomás de Aquino o conhecimento por descoberta se dá quando a razão, por si mesma, aplica os princípios universais e evidentes a determinadas matérias, tirando assim conclusões particulares, a aquisição do conhecimento pelo ensino acontece quando este processo natural e dedutivo da razão passa de princípios universais para conclusões particulares, mediante a ajuda de um intermediário: o professor. O professor, através de sinais e outros instrumentos de ajuda, provoca o aluno e o faz chegar a conhecer o que antes desconhecia. Assim, "ao contrário de Agostinho, Aquino não acredita que é preciso de uma iluminação divina para conhecermos as verdades naturais, sendo o aprendizado uma faceta humana, pois, para ele, 
é o indivíduo quem conhece e ensina, por ser dotado naturalmente de virtudes intelectuais, atuando assim com justiça, temperança, fortaleza e prudência, para tanto exigindo educação" (CAVALCANTE E OLIVEIRA, 2009, p. 14).

Jean-Jacques Rousseau (1712-1778), considerado o pai da educação moderna, criticou severamente a educação tradicional, propondo que as crianças fossem levadas a sério, provocando uma verdadeira revolução filosófica. Rousseau afirma, em sua obra educacional, de 1762, Emílio ou Da Educação, que a "teoria e a prática educacional deveriam pensar nas necessidades das crianças e nas condições de seu desenvolvimento. Nisso consiste a ideia de que, a criança não podia ser mais entendida como um adulto em miniatura. Cada fase da vida: infância, adolescência, juventude e maturidade foram concebidas como portadoras de características próprias, destacando que o adulto, sabendo quais são os pensamentos, sentimentos e interesses das crianças, não irá impor os seus” (VALEIRÃO, 2014, p. 19).

Karl Marx (1818-1883), filósofo do materialismo histórico, combinou o estudo das ciências humanas com a militância revolucionária, sendo coerente com a ideia de que os filósofos haviam interpretado o mundo de várias formas, cabendo agora transformá-lo. O seu pensamento fundou diversas e diferentes correntes pedagógicas comprometidas com a mudança da sociedade, pois entendia que a educação ao mesmo tempo, intelectual, física e técnica, comprometida nas duas dimensões: denunciar as ideologias e anunciar uma nova realidade social. "Revolucionou a pedagogia ao indicar que não é a vida que gira em volta das ideias, mas que são as ideias que giram em volta da vida, invertendo assim a dialética de Hegel, onde a pedagogia deve conceber principalmente a vida e não as ideias, devendo conhecer os homens reais sob condições concretas e não mais somente as ideias dos homens" (VALEIRÃO, 2014, p. 19).

Dentre os muitos seguidores e discípulos das ideias de Marx, o filósofo italiano Antonio Gramsci (1891-1937) e o educador, patrono da educação brasileira Paulo Freire (1921-1997) destacam-se por vasta produção onde desenvolvem análises profundas da educação tendo por base a teoria marxista, criada a partir da produção filosófica de Marx.

Para Gramsci, a educação deve buscar a emancipação humana a partir da filosofia da práxis (construção de uma nova sociedade), elevando as pessoas do senso comum (conhecimento vulgar) ao bom senso (capacidade de refletir sobre a realidade). A escola unitária, segundo Gramsci, deve reproduzir a ideologia (conjunto de conceitos e valores da 
sociedade) e também questioná-la, promovendo a contraideologia, isso é, a crítica aos elementos da ideologia vigente. A proposta de escola unitária se deve a experiência de Gramsci, que sentiu na pele a miséria dos camponeses sardos, as precárias condições sociais de vida de sua família, o que o levou a defesa de uma educação socialmente igualitária, ou seja, igual para todos, oferecida pelo Estado que tivesse como parâmetros a cultura, o conhecimento científico e, a autogestão política, a qual tem direito todos os sujeitos sociais enquanto cidadãos, dirigentes de suas próprias destinações históricas (MELO E RODRIGUES, 2016, p. 2).

Paulo Freire firma a fundamentação para as suas propostas práticas no pensamento de Marx e Gramsci, fazendo da exploração do senso comum em busca do bom senso uma didática emancipatória diferenciada da educação bancária, transmissão de informações como se o aluno fosse apenas um depósito. "A proposta metodológica de Freire tem como ponto de partida a realidade concreta e as experiências significativas, fazendo da pedagogia compromisso com o enriquecimento do ser" (VALEIRÃO, 2014, p. 19).

Segundo Ecco e Nagoro (2015), com Freire reafirma-se categoricamente a educação como processo de humanização, e seu sentido decorre da incompletude dos seres humanos, os quais precisam modificar-se, necessidade da natureza humana, em face da inevitabilidade de complementarem-se como pessoas, concretizando sua vocação de "Ser-Mais". Entretanto, a condição humana não exclui outra possibilidade, que consiste em Ser-Menos: "A humanização enquanto vocação tem, na desumanização, sua distorção" (FREIRE, 1994, p. 184). Por isso, o fazer educativo pode constitui-se num fazer incoerente. A grande contribuição da concepção freireana de educação está contida na afirmação de que os humanos se educam em comunhão, mediados por determinado objeto de conhecimento, particularmente, a realidade vivida: "Ninguém educa ninguém, como tão pouco ninguém se educa a si mesmo: os homens se educam em comunhão, mediatizados pelo mundo" (FREIRE, 1983a, p. 79).

\subsection{O Ensino de Filosofia na Educação Brasileira}

A presença do ensino de Filosofia no ensino médio tornou-se questão muito estudada e debatida em nosso país, tendo as discussões aflorado com maior intensidade após o término do regime ditatorial cívico-militar (1964-1985). No ano de 1996 foi aprovada a Lei 9. 394/96 de Diretrizes e Bases da educação Nacional, LDB, trazendo transformações no contexto escolar e ampliando a discussão acerca da existência do ensino de Filosofia no ensino médio, tais discussões levaram à promulgação da Lei 11.684/2008, a qual tornou o ensino de Filosofia 
obrigatório, porém antes mesmo da obrigatoriedade completar uma década, a Lei 13.415/2017 aprova alterações na LDB retirando a obrigatoriedade.

Em 22 de setembro de 2016, logo após o impedimento da presidenta Dilma Roussef e tendo se passado 22 dias da posse de Michel Temer como presidente da República, é lavrada a Medida Provisória (MP) n ${ }^{o}$ 746/2016, constando na Exposição de Motivos, do texto encaminhado ao Congresso Nacional, que a mesma almeja "dispor sobre a organização dos currículos do ensino médio, ampliar progressivamente a jornada escolar deste nível de ensino e criar a Política de Fomento à Implementação de Escolas de Ensino Médio em Tempo Integral" (BRASIL, 2016a). Alguns dos aspectos presentes no texto da MP no 746/2016 chamaram imediata atenção da mídia, em especial duas situações: a extinção da obrigatoriedade de quatro disciplinas - Sociologia, Filosofia, Artes e Educação Física - e a possibilidade de atribuição do exercício da docência a pessoas com "notório saber" em alguma especialidade técnicoprofissional (FERRETI e SILVA, 2017, p. 386).

Ao observarmos a história da educação brasileira é possível constatar que o ensino de Filosofia esteve constantemente pautado na intenção de adequar intelectualmente aos interesses instrumentais dos sistemas vigentes, não lhe permitindo uma radicalidade filosófica (BITTENCOURT, 2015, p.27).

Historicamente o ensino de Filosofia chega ao sistema educacional brasileiro durante o período colonial, com os jesuítas no século XVI, onde ensino e os conteúdos eram direcionados para o estudo de autores, a partir das obras fosse possível a manutenção da dogmática cristã, tendo um caráter fortemente dogmático e impregnado de ideologia tomista (GALLO, 2004, n.p.).

Nesse momento a Filosofia estava intrinsecamente vinculada ao trabalho catequético da Igreja Católica Romana no Brasil, porém representa, ainda assim, os primeiros fundamentos e práticas sistemáticas da educação brasileira, cabe aqui ressaltar que o sistema educacional brasileiro destinada apenas a uma pequena elite da população e marcada fortemente por influências eurocêntricas (SILVA, 2018, p. 15).

No período imperial, século XIX, há uma grande efervescência intelectual, na produção literária, jornalística e também filosófica, influenciada por filósofos e movimentos filosóficos europeus como o kantismo, idealismo alemão, romantismo e positivismo (BITTENCOURT, 2015, p. 28).

No século XX, o advento da república no fim do século XIX e a forte influência do positivismo comteano, leva a Filosofia a uma considerável perda de importância nos currículos da educação média, ficando centrada na lógica e na epistemologia (GALLO, 2004, n.p.). Cabe 
ressaltar que positivismo comteano tinha como propósito relegar a Filosofia à propedêutica das ciências naturais e lógicas, pois estas sim deveriam ser os verdadeiros objetos de estudo a ser praticado, de maneira que o ensino de Filosofia fosse voltado para a iniciação à ciência (SILVA, 2018, p. 16).

Nas décadas de 1920 e 1930 a disciplina de Filosofia firma-se nos currículos das instituições de formação docente, assumindo a dupla função de preservar os fundamentos morais, apoiados nos princípios da metafísica, da teologia cristã e quando os conteúdos eram remodelados pelas novas tendências, apoiados nos princípios e preceitos científicos originados pela Escola Nova. A dupla tarefa da filosofia firmou-se apoia nos pressupostos filosóficos de Kant, Rousseau, William James e Dewey, bem como também pela filosofia tomista. Cabe ressaltar que a Escola Nova recomendava uma metodologia apoiada em uma filosofia progressista de caráter liberal, assim a filosofia como disciplina buscava preceitos da modernidade e os seus fundamentos para a formação do homem (ZANATTA, 2008, p. 3451).

\begin{abstract}
A real difusão da Filosofia e a prática de seu ensino só ocorreu a partir da década de 1940 com a missão francesa na Universidade de São Paulo (USP), pois até então a mesma sempre esteve atrelada somente ao tomismo jesuítico, aos cursos superiores que D. João VI e os monarcas posteriores fundaram no Rio de Janeiro, bem como também ao ensaísmo, leve e descompromissado que os mestres de tais cursos provocavam. Assim, com a chegada de professores franceses a Filosofia e o seu ensino alcançam outro patamar, imprimindo no Brasil um conceito e uma metodologia filosófica até então inédita (PINHO, 2014, p. 761).
\end{abstract}

Em 1942, ocorre a Reforma Capanema, a qual teve por objetivo atender a formação integral do adolescente, de maneira a manter a consciência patriótica e humanística, bem como a preparação para servir de base aos estudos superiores. Nesta reforma, os ciclos de ensino permaneceram divididos em dois: o primeiro chamado de ginásio, com duração de quatro anos e o segundo de colegial, com duração de três anos, podendo o colegial ser clássico, voltado para uma formação intelectual ou científico, voltado para uma formação de ênfase no ensino das ciências. Tanto no curso clássico, como no curso científico a Filosofia era disciplina obrigatória (DUTRA E PINO, 2010, p. 89).

Cabe ressaltar, que de cunho obrigatório a partir da reforma Capanema, inicialmente a disciplina filosofia constava nos currículos do $2^{\circ}$ e $3^{\circ}$ ano do curso colegial clássico e no $3^{\circ}$ ano no curso do colegial científico, onde inicialmente eram ministradas, semanalmente, quatro aulas nas turmas do $2^{\circ}$ ano e duas aulas no $3^{\circ}$ ano do clássico e no científico eram ministradas semanalmente quatro aulas no $3^{\circ}$ ano. Porém, em 1945, ocorre uma mudança onde permanecem 
as quatro aulas semanais no $3^{\circ}$ ano do curso científico, e nos $2^{\circ}$ e $3^{\circ}$ anos do clássico passam a ser ministradas três aulas semanais. Em 1954, ocorre nova alteração e passam a ser ministradas aulas nos dois cursos, clássico e científico. Sendo reduzido para apenas duas aulas nas séries do clássico e uma aula no curso científico, em 1954 (CESAR, 2012, p. 4).

De acordo com Silva (2018, p. 18), mesmo com a legalização nas escolas, o ensino de Filosofia não encontra um espaço realmente estabelecido e valorizado, fica claro a presença de um conflito ideológico nas diversas práticas escolares deste período, por um lado, temos com a Constituição de 1946 e a Política Desenvolvimentista da década de 1950, marcas de um modelo liberal democrático, onde a educação é pensada voltada ao conhecimento técnico-científico. De outro lado, influenciados pelo movimento dos pioneiros da educação, ocorrem várias iniciativas para uma educação humanista. Assim, para o autor, o ensino de Filosofia é muitas vezes visto e tratado como inconveniente ou de pouca relevância. Em meio a tantos embates e depois de anos de elaboração e reelaboração é promulgada a primeira Lei de Diretrizes e Base da Educação Nacional do Brasil - LDB 4.024/61, na qual o ensino de Filosofia torna-se complementar, ficando sob a responsabilidade de cada Conselho Estadual de Educação a sua aplicação ou não, o que na prática não representou uma maior inserção nem do ensino de Filosofia, nem de outras disciplinas afins, além do que já se praticava.

Para Bittencourt (2015, p. 28) durante os anos do regime ditatorial civil-militar brasileiro (1964-1985) o ensino de Filosofia foi distorcido por meio da criação da disciplina Educação Moral e Cívica, a qual segundo o autor foi idealizada por educadores tecnocratas intrinsecamente aliados ao regime com o objetivo de introduzir e moldar as mentes dos jovens a partir de um conjunto de conteúdos normativos, para que assim a juventude brasileira adequasse a sua conduta aos interesses do poder estabelecido, fortemente marcado pela repressão a qualquer tipo de comportamento ou ideia crítica que o contesta. Assim, era ofertado aos alunos e alunas uma série de conteúdo desta filosofia, caracterizada pelo apagamento das contradições fundamentais da política, bem como também por forte apelo ao respeito às estruturas, postas como estruturas tradicionais da sociedade, a exemplo a família e a religião cristã, de maneira a produzir um efeito alienante nos estudantes, para que não apresentassem qualquer manifestação de discordância em relação a ordem imposta.

Fica evidente que o pensar crítico e transformador que caracteriza a atividade filosófica constituíam uma ameaça à ordem vigente, ou seja, a regime ditatorial, imposto ao país, em decorrência de que ele propõe a formação de consciências que pudessem refletir sobre os 
problemas reais da sociedade. Assim, surge a necessidade da implementação da disciplina de educação moral e cívica em substituição do ensino de Filosofia. Desta maneira, a LDB n $5692 /$ 71 reorganizou o ensino de $1^{\circ}$ e $2^{\circ}$ graus (antigos primário, ginásio e colégio), voltada para as necessidades da época atual, eminentemente tecnológica, propondo uma educação profissionalizante, legitimando o abandono da filosofia, que não fez parte do núcleo comum do currículo de $1^{\circ}$ e $2^{\circ}$ graus, para em seu lugar apresentar às disciplinas "educação moral e cívica" e “organização social e política do Brasil” (CESAR, 2012, p. 6).

No início da década de 1980, ocorre o começo de um retorno da Filosofia ao currículo do ensino médio, depois de muita luta e discussão, vindo a ocorrer de maneira muito diferenciada em cada estado brasileiro, citando o caso de São Paulo, por exemplo, o retorno se deu como uma disciplina optativa, onde a direção de cada escola era livre para aderir a sua inclusão ou não, por meio da escolha de duas disciplinas entre filosofia, sociologia e psicologia, em ao menos uma série do que na época era chamado segundo grau (GALLO, 2004, n.p).

Desde o final do regime militar, ocorrido em 1985, e mesmo antes, ocorreram diversas mobilizações de educadores e filósofos em para a volta da Filosofia no ensino médio, mobilizações que resultaram no artigo 36 da LDB $\mathrm{n}^{\circ}$ 9394/1996 que determinava que ao final do ensino médio, os estudantes deveriam dominar os conhecimentos de filosofia e sociologia necessários ao exercício da cidadania (CESAR, 2012, p. 6).

Uma conquista importante na luta pela obrigatoriedade do ensino de Filosofia no ensino médio foi a proposta de projeto de Lei 3.178/1997 do então deputado federal Padre Roque (PTPR), o qual tinha por objetivo modificar a LDB 3. 394/1996 de maneira a tornar obrigatório a inclusão da disciplina por todos os Estados brasileiros nos seus currículos nas três séries do ensino médio. O projeto chegou a ser aprovado pela Câmara e pelo Senado Federal, no ano de 2001, sendo vetado pelo então Presidente da República, o sociólogo Fernando Henrique Cardoso. A inclusão da disciplina de Filosofia, retornou a se efetivar, somente cinco anos após o voto por meio do Parecer CNE/CEB 38/2006, tendo sua inclusão efetivada no ano de 2008, através da entrada em vigor da lei 11. 684/08, medida que tornou efetivamente obrigatório o ensino de Filosofia em todas as séries do Ensino Médio (DUTRA E PINO, 2010, p. 90).

Sucessivas foram as tentativas e alterações que pautaram a questão da reforma do ensino médio após a LDB 9.394/96, várias iniciativas de propostas de mudanças por parte do Governo Federal e do Congresso Nacional, foram sendo realizadas com mais ou menos sucesso e abrangência, propostas que tem origens de segmentos sociais, de instituições com interesses econômicos e ideológicos, as quais culminam com alteração na legislação educacional 
brasileira que modificou novamente o cenário da legalidade com relação ao ensino de Filosofia na escola, no ano de 2017, e assim, menos de uma década da obrigatoriedade, a disciplina de Filosofia deixa novamente de ser obrigatória (SILVA, 2018, p.29).

A alteração na LDB, chamada popularmente de Reforma do Ensino acontece em um contexto triste da história política e social do Brasil, marcado pela aprovação pelo Senado Brasileiro do impedimento da então presidenta Dilma Rousseff, no dia 31 de agosto de 2016, cabe ressaltar que antes mesmo da conclusão do processo de Impedimento, ainda na instituição de um governo provisório, o presidente em exercício Michel Temer e sua equipe começaram a propor reformas no Estado brasileiro de grande envergadura e impacto.

\section{Por Que Ensinar Filosofia No Ensino Médio?}

A urgência da discussão acerca do ensino de Filosofia no contexto educacional brasileiro contemporâneo faz ressurgir um debate amplo e que está longe de chegar a um consenso. O que ensinar, como ensinar, para quem ensinar são interrogações que emergem no contexto dessas discussões e que tem reflexo direto nos estudantes Ensino Médio brasileiro. Ao olhar para a história do ensino de filosofia no Brasil fica explícito que o mesmo nem sempre recebeu a devida importância no conjunto das disciplinas a serem ensinadas, passando por momentos de total exclusão do currículo do ensino básico. Isso por muitas vezes ter sido vista com desconfiança por agentes públicos que viam nela um mal a ser extirpado, afinal a Filosofia leva os indivíduos a refletir, pensar, criticar, sendo tachada de uma ameaça a ser contida (SILVEIRA, 2015, p. 76).

Para Bittencourt (2015, p. 27), em uma sociedade de orientação ideológica tecnocrática e moralmente conservadora como a brasileira, a presença da atividade filosófica, exercida com dignidade profissional e compromisso intelectual, moral e ético, sempre causa desconforto e incômodo indo de encontro as classes e grupos reacionários, os quais são expressões das contradições estruturais existentes na organização social. Para o autor, a Filosofia tem o papel cáustico de dissolver as bases não refletidas presentes em nosso modo de viver e em nossas manifestações sociais, culturais e políticas.

Assim, filosofar é nadar contra a maré, pois onde a atividade filosófica exerce sua reflexão radical, a massificação alienante, presente em diversos segmentos sociais, se coloca pronta para afrontar sua dignidade, fazendo da presença do ensino de Filosofia, mero 
cumprimento de exigências pedagógicas dos currículos, onde muitos não reconhecem no discurso filosófico uma possibilidade de abertura de consciência para as reflexões críticas acerca da vida humana em sua interação com o mundo material (BITTENCOURT, 2015, p. 27).

Silveira (2015, p. 89) afirma que a Filosofia permite aos estudantes o desenvolvimento de um senso crítico, que os permita atuar de maneira protagonista, crítica e consciente na sociedade e como sociedade. Para tanto deve se buscar um ensino de Filosofia que reconheça, valorize e promova o agir reflexivo do ser humano em busca de sua emancipação, onde devemos conhecer os processos que perpassam por detrás de sua presença na sala de aula. É preciso conhecer sua história, suas contradições e conflitos, sua estruturação enquanto disciplina escolar, a fim de que a conhecendo, possamos ter argumentos e embasamentos que possibilitem solidificar o processo construtivo de seu currículo evitando, cada vez mais, o ensino tecnicista, e buscando torná-lo cada vez mais humano, e próximo da realidade políticosocial de seus aprendizes (DUTRA E PINO, 2010, p. 92).

Segundo Zanatta (2008, p.3446) a educação, se pronuncia na voz dos educadores que procuram, uma forma de transformação que possa acompanhar os novos tempos. Buscando conhecer as expressões e as proposições educativas, presente nos discursos dos educadores, tanto na tentativa de delinear diferentes caminhos para a educação quanto ao desejar prosseguir no caminho que, até então, educacionalmente estava traçado, encontra-se uma filosofia de inspiração educativa. O que permite, perceber por meio, estas expressões que, na maioria, são de caráter argumentativo sendo possível encontrar vestígios de uma filosofia de estilo nacional ainda que transpareça interferências internacionais. Onde é possível identificar maneiras brasileiras de filosofar.

Um estilo do filosofar brasileiro no âmbito educacional se caracteriza e se constitui sob a ótica de dois segmentos: o tradicional que incorpora um modelo filosófico influenciado pelo pensamento de determinados autores de modelos clássicos da filosofia ocidental e o progressista que reconhece as condições históricas que estão se apresentando e que requer uma educação inovadora (ZANATTA, 2008, p.3446).

Desde a antiguidade que a Filosofia tem sido uma aliada do ensino, não se constituindo essa relação num problema para a Filosofia em si. Ela não deixará de ser uma atividade crítica, somente porque é aprendida/ensinada na escola. É preciso reconhecer que uma má pedagogia poderá fazer com que a Filosofia fracasse, no entanto, quando o método pedagógico é o mais 
adequado e assertivo, a Filosofia é perfeitamente ensinável, como qualquer outra disciplina. Se, como postula Platão, a Filosofia é essencial à escola, também é verdade que a escola é essencial à Filosofia. No fundo, a Filosofia é uma tarefa que se ensina e que se aprende, não podendo, por isso, ser banida da escola. A escola é uma dessas estruturas de coordenação e produção de sentido, tudo indicando que a filosofia não pode dela prescindir. O que importa é que tanto a escola como a filosofia sejam obra da razão, não apenas ultrapassado resultado de um racionalismo que se une bem com o formalismo escolar institucional e com o escolasticismo filosófico. Deste modo, as questões que se colocam são as de saber quem ensina, e sim quem aprende e o que se ensina/aprende em Filosofia (PINHO, 2014, p. 765).

Apesar das adversidades, a atividade filosófica no Brasil encontra razoável respaldo editorial, de modo que gradativamente se amplia o público leitor de textos filosóficos, independentemente de haver ou não uma orientação de estudos, pois a autonomia é um dos princípios filosóficos, e cabe ao próprio indivíduo desenvolver tal capacidade em suas reflexões intelectuais. É preciso considerar a virtualização da comunicação, que a apesar do grande volume de conteúdos falsos e inoportunos divulgados na Internet, tem permitido uma significativa presença de intelectuais exprimindo suas ideias nas redes (BITTENCOURT, 2015, p. 34). Um exemplo é a nova geração de mulheres filósofas e pensadoras, principalmente as expoentes da Teoria Política Feminista, que fazem uso da internet para divulgarem seus trabalhos e exporem suas teorias, como a filósofa brasileira Djamila Ribeiro e as filósofas da Rede Brasileira de Mulheres Filósofas ${ }^{3}$.

A filosofia é, possivelmente, o campo de saber mais plurívoco e, portanto, aberto e suscetível de muitos equívocos. Não se pode falar em 'filosofia' de forma geral, sem dizer de que filosofia falamos. Da mesma maneira, não se pode falar em 'ensinar filosofia' como se se tratasse de algo geral e universal. Enunciando de forma um pouco diferente o que foi afirmado acima, falar em ensinar filosofia é falar em ensinar uma determinada filosofia, ou ensiná-la a partir de uma determinada perspectiva (GALLO, 2012, p.38).

Assim, o pensamento dos filósofos, as diferentes filosofias, devidamente contextualizadas, passam a constituir os referenciais teóricos e metodológicos (conceitos, categorias analíticas, teorias, métodos de refletir) para a compreensão e a crítica dos temas problemas abordados no ensino de Filosofia, de maneira que o contato dos alunos e alunas com

\footnotetext{
${ }^{3}$ Rede de Mulheres Filósofas que tem por objetivo lutar contra o preconceito acadêmico, dar visibilidade à obra de filósofas, discutir questões de feminismo e gênero e, principalmente, fazer filosofia: objetivo final de seus interesses. Formam um coletivo de profissionais brasileiros engajados em projetos sobre filosofia e mulheres. Site https://www.filosofas.org/
} 
o pensamento desses autores, mediado pelo professor, os permita perceber seu próprio estilo pensar, sua forma de perguntar, de indagar, de se distanciar do senso comum, de assumir uma atitude crítica, ou seja, de problematizar a realidade de seu tempo e lugar, constituindo (SILVEIRA, 2011, p. 152).

\section{Conclusão}

Como ficou evidenciado na apresentação cronológica da história do ensino de filosofia na educação brasileira, o Estado sempre executou e priorizou políticas educacionais que seguiam os desejos do capital internacional, das elites e classes burguesas brasileiras, podendo ser entendido nas palavras de Marx (1848) como um "comitê para gerir os negócios da burguesia". Apesar de aparentar neutralidade num contexto marcado por interesses de classe antagônicos, o Estado na verdade atende aos processos de acumulação e legitimação do capital, marginalizando os interesses da maioria trabalhadora, e de maneira bastante evidente os trabalhadores e trabalhadoras rurais.

Uma das lutas do Movimento de Trabalhadores Sem Terra (MST) juntamente a reforma agrária foi pela pauta de uma educação que permitisse aos jovens exererem o papel da juventude na desefa pelo direito à Educação Pública, Popular e Libertadora ${ }^{4}$, assim as crianças e adolescentes, filhas e filhos das famílias Sem Terra, moradores nos assentamentos de Reforma Agrária em Hulha Negra, na companhia de pais ocupam a terra para ter alimentos, casa para morar, lugar de brincar, estudar e ser feliz. É de suma importância para o MST a conquista de uma educação voltada para a realidade camponesa, onde as teorias e saberes sejam artiulados com a produção dos alimentos que são consumidos, com os aprendizados de formas de preservar o meio ambiente, de cuidar do lixo, de refletir os riscos do uso de agrotóxicos, contemplando também oficinas, palestras, visitas de estudo, atividades e noites culturais, místicas, auto-organização e plano de estudo.

Assim, o trabalho de observação do ensino de filosofia na Escola se demonstrou enriquecedor por permitir a experiência de observação das relações entre educadores e educandos a partir do desenvolvimento de uma pertença ao grupo escolar e a comunidade onde estão inseridos, sendo entendido como pertença a ação consciente de reconhecer-se como integrante de uma comunidade e de maneira que este sentimento os motivem a firmarem seus

\footnotetext{
${ }^{4}$ https://mst.org.br/2019/07/15/continuaremos-a-luta-e-a-defesa-da-educacao-do-campo-e-do-mst/
} 
ideais, recriam formas de convivência e de valores de geração a geração, sendo esses os sentimentos fundamentais na formação da identidade com o campo, a educação e a cidadania.

A experiência de estagiar junto as turmas de ensino médio da Escola 15 de Junho me permitiu refletir sobre as teorias da educação, o ensino de filosofia e a prática filosófica, me fazendo recordar as palavras de Freire, quando ele nos afirma que reflexão crítica sobre a prática se torna uma exigência da relação teoria/prática, pois na qual a teoria pode vir a virar blá-bláblá.

Segundo Freire (2018, p. 24), o formando desde o início de sua experiência formadora, assumindo-se como sujeito também da produção do saber, se convença definitivamente de que ensinar não é transferir conhecimento, mas criar as possibilidades para a sua produção ou a sua construção. Assim, quem ensina aprende ao ensinar e quem aprende ensina ao aprender. Esse foi meu objetivo ao escolher a escola 15 de Junho, aprender a ensinar e aprender ensinando. Neste contexto de descaso e ataques à educação, estar em sala de aula é um ato de resistência, especialmente em sala de aula de escola da educação do campo que exige uma teoria ajuizada pela prática que, objetiva construir saberes que permitam o desenvolvimento integral de alunos e alunas, para que possam exercer seu papel social de cidadãos e cidadãs de uma sociedade democrática.

A escola 15 de Junho, sendo uma escola fruto da luta pela construção de uma educação que atenda a demanda educacional voltada a realidade rural, camponesa, busca assim ter por base os princípios norteadores da Educação do Campo, desenvolvendo percursos educativos com bases na criticidade, debruçando-se principalmente na realidade vivênciada por seus alunos e alunas, objetivando superar concepções marginalizadoras sobre seus modos de vida, e deixando postas as contradições socioeconômicas que vem ameaçando suas existências no território rural.

A escola tem a educação como instrumento para a desconstrução de estruturas de desigualdade, e colocando-se como agente fundamental nas relações sociais e históricas, que buscam estruturar as relações em sociedade alicerçadas em princípios de igualdade e equidade. O ensino da Filosofia, dentro da estrutura escolar, permite capacitar adolescentes e jovens para o diálogo, para o debate de ideias, garante a oportunidades destes estudantes possam desenvolver seus próprios pensamentos e não apenas reproduzir ideias sem um discernimento crítico. Trata-se de não permitir que estes jovens permaneçam absorvidos pelo senso comum, 
mas possam aprofundar uma consciência crítica da realidade na qual estão inseridos, podendo vir a tornarem agentes de transformação social.

A Filosofia está associada não apenas à um saber teórico mais também a uma sabedoria prática, o que pode ser muito bem observado nas observações referentes ao período no qual estive estagiando nesta escola, por meio das atividades de cunho interdisciplinar e o incentivo dado pela PR para que os alunos e alunas se coloquem frente a realidade a sua volta, como agentes críticos e reflexivos, de maneira que os conteúdos abordados e estudados em sala de aula e em trabalhos extraclasse fossem sempre balizados de maneira dialética pelas suas experiências e vivências pessoais e coletivas junto à comunidade na qual estão inseridos. Confirmando a validade da hipótese levantada, de que o Ensino de Filosofia contribui para a formação de indivíduos emancipados, indo ao encontro da proposta educacional da educação no/do campo, a qual tem por base as contribuições do educador brasileiro Paulo Freire e forte influência do processo pedagógico do Movimento dos Trabalhadores Sem-Terra (MST). 


\section{REFERÊNCIAS BIBLIOGRÁFICAS}

ARANHA, Maria Lúcia Arruda; Martins, Maria Helena Pires. Filosofando: Introdução à Filosofia. Livro Didático. São Paulo: Moderna, 2012, p.15.

BRASIL. Congresso Nacional. Projeto de Lei $\mathrm{n}^{\mathrm{o}}$ 6.840/2013. 2013. Disponível em: https://www.camara.leg.br/proposicoesWeb/prop_mostrarintegra?codteor=1200428\&filenam $\mathrm{e}=\mathrm{PL}+6840 / 2013$

BARBOSA, Evandro. Metodologia e Prática de Pesquisa em Filosofia. Pelotas: NEPFIL on line, 2015.

BITTENCOURT, Renato Nunes. Pela Afirmação da Importância da Filosofia no Ensino Médio Brasileiro. Revista Espaço Acadêmico. Maringá, n.171, p. 26-37, agosto, 2015. Disponível em http://www.periodicos.uem.br/ojs/index.php/EspacoAcademico/article/view/28594/14965.

CAVALCANTE, Tatyana Murer; OLIVEIRA, Terezinha. Contribuições de Tomás de Aquino para a educação: as virtudes cardeais e o bem comum. Seminário de Pesquisa do PPE, 2009, Pelotas. Anais... Pelotas, Disponível em: http://www.ppe.uem.br/publicacoes/seminario ppe 2009 2010/pdf/2009/12.pdf

CESAR, Renata Paiva. O ensino de Filosofia no Brasil. Revista Pandora Brasil. [S.L.], n. 38, p. $1-11$ 2012. Disponível em: http://revistapandorabrasil.com/revista_pandora/renata/o_ensino_brasil.pdf

DUTRA, Jorge da Cunha; PINO, Mauro Augusto Burkert Del. Resgate Histórico do Ensino de Filosofia nas Escolas Brasileiras: do século VXI ao século XXI. InterMeio: Revista do Programa de Pós-Graduação em Educação. Campo Grande, v.16, n.31, p. 85-93, 2010. Disponível em: http://repositorio.furg.br/xmlui/bitstream/handle/1/1397/Resgate\%20hist\%C3\%B3rico\%20do $\% 20$ ensino\%20de $\% 20$ Filosofia\%20nas $\% 20$ escolas $\% 20$ brasileiras. $\% 20$ do\%20seculo $\% 20 \mathrm{XVI}$ $\% 20 \mathrm{ao} \% 20$ seculo $\% 20 \mathrm{XXI} . p d f ?$ sequence $=1$

ECCO, Idanir; NAGORO, Arnaldo. A Educação em Paulo Freire como Processo de Humanização. XII Congresso Nacional de Educação: Educere, 2015, Curitiba. Anais...

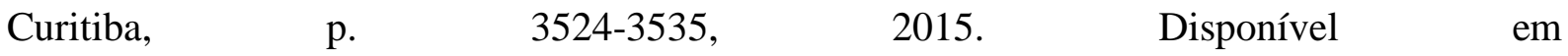
https://educere.bruc.com.br/arquivo/pdf2015/18184_7792.pdf

FERRETI, Celso João; SILVA, Mônica Ribeiro da Reforma do Ensino Médio no Contexto da Medida Provisória $n^{\circ}$ 746/2016: Estado, Currículo e Disputas por Hegemonia. Educ. Soc., Campinas, v. 38, no. 139, p.385-404, abr.-jun., 2017.

FREIRE, Paulo. Cartas a Cristina. Rio de Janeiro: Paz e Terra, 1994.

FREIRE, Paulo. Educação como prática da Liberdade. 14. ed. Rio de Janeiro: Paz e Terra, 1983b. 
FREIRE, Paulo. Pedagogia da Autonomia; saberes necessários à prática educativa. $57^{\circ}$ ed. São Paulo/Rio de Janeiro: Paz e Terra, 2018.

FREIRE, Paulo. Pedagogia da Esperança; um reencontro com a Pedagogia do Oprimido. $23^{\circ}$ ed. São Paulo/Rio de Janeiro: Paz e Terra, 2016.

GALLO, S. A função da filosofia na escola e seu caráter interdisciplinar. Revista Sul Americana de Filosofia e Educação, n.2, mai./out. 2004. Disponível em: https://periodicos.unb.br/index.php/resafe/article/download/3919/3590/

GALLO, Silvio. Metodologia do ensino de filosofia: uma didática para o ensino médio. Campinas: Papirus, 2012, p.28.

MELO, Maria Lúcia; RODRIGUES, Denise Simões. Gramsci e a Educação. I Joingg - Jornada Internacional De Estudos E Pesquisas Em Antonio Gramsci Vii Joregg - Jornada Regional De Estudos E Pesquisas Em Antonio Gramsci. Práxis, Formação Humana e a Luta por uma Nova Hegemonia Universidade Federal do Ceará - Faculdade de Educação, Anais... Fortaleza, 2016. Disponível em: http://www.ggramsci.faced.ufc.br/wp-content/uploads/2017/06/GRAMSCI-EA-EDUCA\%C3\%87\%C3\%830.pdf

PAGNI, Pedro Angelo. A filosofia da educação Platônica: o desejo de sabedoria e a Paideia Justa. Acervo Digital da Unesp. Objetos educacionais, 2010. Disponível em https://acervodigital.unesp.br/handle/123456789/126?mode=full

PINHO, Romana Isabel Brázio Valente. O Ensino de Filosofia no Brasil: Considerações Históricas e Político-legislativas. Revista Educação e Filosofia. Uberlândia, v.28, n.56, p. 757771 , 2014.

Disponível

em: http://www.seer.ufu.br/index.php/EducacaoFilosofia/article/view/22472

PLATÃO. República. Rio de Janeiro: Editora best Seller, 2020. Tradução Enrico Corvisieri.

RUBANO, D. R.; MOROZ, M. O conhecimento como ato da iluminação divina: Santo Agostinho. In: ANDERY, M. A. et al. Para compreender a ciência: uma perspectiva histórica. 10. ed. Rio de Janeiro: Garamond; São Paulo: EDUC, 2001.

SANTOS, Joanita F. Almeida dos; KANBEN, Andréa. A Importância da Educação no Cenário da Educação do Campo: Um Estudo de Revisão. Repositório Digital Institucional Universidade Federal do Paraná. Paraná, 2015. Disponível em http://hdl.handle.net/1884/383994

SILVA, Cristian Fabrício dos Santos. A Contribuição do Ensino de Filosofia no Ensino Médio Profissionalizante do IFPB. Dissertação (Mestrado em Formação de Professores) Universidade Estadual da Paraíba, Campina Grande, 2018. Disponível em http://posgraduacao.uepb.edu.br/ppgfp/download/DISSERTACAO-CRISTIAN-FABRICIO-DOS-

SANTOS-SILVA.pdf

SERRA, Elpídio. SOBRINHO, Alaíde Paulino. A Proposta Pedagógica do MST e as Escolas de Campo. Revista Boletim de Geografia. Departamento de Geografia da Universidade Estadual de Maringá. Maringá, v.31, n2, p. 143-152, maio-ago, 2003. 
SILVEIRA, Thiago Coelho. Ensino de Filosofia no Ensino Médio: uma análise do Livro Iniciação à Filosofia de Marilena Chauí. Caderno do PET Filosofia, [S. L.], v. 6, n. 11, p. 75 92, 2015. Disponível em https://revistas.ufpi.br/index.php/pet/article/view/3655

SILVEIRA, Renê José Trentin. Ensino de Filosofia de uma perspectiva históricoproblematizadora. Educação em Revista. Marília, v. 12, n.1, p. 139-154, 2011. Disponível em: http://www2.marilia.unesp.br/revistas/index.php/educacaoemrevista/article/view/1544

SOUZA, Mariana Rossetto; PEREIRA MELO, José Joaquim. A Educação em Santo Agostinho: processo de interiorização na busca pelo conhecimento. IX Congresso Nacional de Educação - EDUCERE, III Encontro Sul Brasileiro de Psicopedagogia. Curitiba, Anais..., p. 2457-2468, 2009. Disponível em https://educere.bruc.com.br/arquivo/pdf2009/1937_1302.pdf

SPONVILLE, André Comte. Dicionário de Filosofia. São Paulo, 2003.

TEIXEIRA, Miguel Henrique Benetti; WOLFF, Andrea Aníbia Ferreira; SOUZA, Débora Martins de; OLIANI, Luiz Henrique. A Contribuição de Sócrates para o método de ensino aprendizagem a distância. Revista Científica UNAR, Araras, v.11, n.2, p.43-52, 2015. Disponível em http://revistaunar.com.br/cientifica/documentos/vol11_n2_2015/4A\%20CONTRIBUI\%C3\%87\%C3\%830\%20DE\%20S\%C3\%93CRATES\%20PARA\%20O\% 20M\%C3\%89TODO\%20DE\%20ENSINO-

APRENDIZAGEM\%20A\%20DIST\%C3\%82NCIA.pdf

TOMÁS DE AQUINO. Sobre o ensino (de magistro) e os sete pecados capitais. Trad. Luiz Jean Lauand. São Paulo: Martins Fontes, 2000.

VALEIRÃO, Kelin. Fundamentos da Educação. NEPFIL online: Série Dissertatio-Incipiens. Pelotas, 2014. Disponível em https://wp.ufpel.edu.br/nepfil/files/2019/02/3-fundamentos-daeducacao.pdf

ZANATTA, Regina Maria; SETOGUTI, Ruth Izumi. Filosofia da Educação no Brasil: Raízes Históricas. VIII Congresso Nacional de Educação: Educere. Curitiba, Anais..., p. 3445-3458, 2008. Disponível em: https://educere.bruc.com.br/CD2013/pdf/8687_6486.pdf 


\section{ANEXO: Quadro A - Observações das Turmas de Ensino Médio}

\begin{tabular}{|c|c|c|}
\hline Data & Carga Horária & Observações \\
\hline $09 / 10 / 2019$ & 01 Período $=50 \mathrm{~min}$ & Conversa com PR, durante preparação da aula. \\
\hline $15 / 10 / 2019$ & 02 Períodos $=100 \mathrm{~min}$ & $\begin{array}{c}\text { Observação da aula turma } 3013^{\circ} \text { Ano - Assunto Direitos } \\
\text { Humanos. }\end{array}$ \\
\hline $21 / 10 / 2019$ & 02 Períodos $=100 \mathrm{~min}$ & $\begin{array}{l}\text { Observação da aula turma 201/3º Ano - Preparação de } \\
\text { Apresentação de trabalhos na Atividade Interdisciplinar. }\end{array}$ \\
\hline $22 / 10 / 2019$ & 03 Períodos $=150 \mathrm{~min}$ & $\begin{array}{l}\text { Apresentação de trabalhos das turmas } 101 / 1^{\circ} ; 201 / 2^{\circ} \text { e } \\
301 / 3^{\circ} \text { nas atividades interdisciplinar "Festa Anos } 80^{\prime} \text { ". }\end{array}$ \\
\hline $04 / 11 / 2019$ & 01 Período $=50 \mathrm{~min}$ & $\begin{array}{c}\text { Observação da aula turma } 201 / 3^{\circ} \text { Ano - Assunto René } \\
\text { Descartes, Filosofia e Crise da metafísica. }\end{array}$ \\
\hline $11 / 11 / 2019$ & 01 Período $=50 \mathrm{~min}$ & $\begin{array}{l}\text { Observação da aula turma 201/3 Ano - Assunto René } \\
\text { Descartes, Filosofia e Crise da metafísica (Continuação). }\end{array}$ \\
\hline $11 / 11 / 2019$ & 02 Períodos = $100 \mathrm{~min}$ & $\begin{array}{c}\text { Observação da aula turma } 101 / 3^{\circ} \text { Ano - Assunto Crise de } \\
\text { Valores e o Conceito de Verdade. }\end{array}$ \\
\hline $12 / 11 / 2019$ & 02 Períodos $=100 \mathrm{~min}$ & $\begin{array}{l}\text { Observação da aula turma } 301 / 3^{\circ} \text { Ano - Preparação de } \\
\text { trabalho a ser apresentado na Feira do Conhecimento }\end{array}$ \\
\hline $13 / 11 / 2019$ & 02 Períodos $=100 \mathrm{~min}$ & Formação de Professores "Dia D" \\
\hline $03 / 12 / 2019$ & 02 Períodos $=100 \mathrm{~min}$ & $\begin{array}{l}\text { Observação da aula turma } 101 / 3^{\circ} \text { Ano - Preparação de } \\
\text { trabalho a ser apresentado na Feira do Conhecimento }\end{array}$ \\
\hline $04 / 11 / 2019$ & 03 Períodos $=150 \mathrm{~min}$ & $\begin{array}{l}\text { Apresentação de trabalhos das turmas } 101 / 1^{\circ} ; 201 / 2^{\circ} \text { e } \\
301 / 3^{\circ} \text { na Feira do Conhecimento da Escola. }\end{array}$ \\
\hline
\end{tabular}

Fonte: Elaborado pelos autores. 